\title{
Reproduction and Sexual Maturity of European Sardine (Sardina pilchardus) in the Central Mediterranean Sea
}

\begin{abstract}
Gualtiero Basilone ${ }^{1}$, Rosalia Ferreri ${ }^{1 *}$, Salvatore Aronica ${ }^{1}$, Salvatore Mazzola ${ }^{1}$, Angelo Bonanno ${ }^{1}$, Antonella Gargano ${ }^{1}$, Maurizio Pulizzi ${ }^{1}$, Ignazio Fontana ${ }^{1}$, Giovanni Giacalone ${ }^{1}$, Pietro Calandrino ${ }^{1}$, Simona Genovese ${ }^{1}$ and Marco Barra ${ }^{2}$

${ }^{1}$ Consiglio Nazionale delle Ricerche, Istituto per lo studio degli impatti Antropici e Sostenibilità in ambiente marino (IAS), Campobello di Mazara, Italy, ${ }^{2}$ Consiglio Nazionale delle Ricerche, Istituto di Scienze Marine, Naples, Italy
\end{abstract}

\section{OPEN ACCESS}

Edited by:

Oscar Sosa-Nishizaki,

Center for Scientific Research and Higher Education in Ensenada

(CICESE), Mexico

Reviewed by:

Khor Waiho,

University of Malaysia

Terengganu, Malaysia

Claudio Vasapollo,

Independent Researcher, Ancona, Italy

${ }^{*}$ Correspondence:

Rosalia Ferreri

rosalia.ferreri@cnr.it

Specialty section:

This article was submitted to Marine Fisheries, Aquaculture and

Living Resources,

a section of the journal

Frontiers in Marine Science

Received: 27 May 2021

Accepted: 02 July 2021

Published: 12 August 2021

Citation:

Basilone G, Ferreri R, Aronica $S$,

Mazzola S, Bonanno A, Gargano A,

Pulizzi M, Fontana I, Giacalone G,

Calandrino $P$, Genovese $S$ and

Barra M (2021) Reproduction and

Sexual Maturity of European Sardine

(Sardina pilchardus) in the Central

Mediterranean Sea.

Front. Mar. Sci. 8:715846

doi: 10.3389/fmars.2021.715846
Understanding drivers of fish maturity is essential to predict the productivity, stability, and resiliency of exploited populations. Size at maturity for European sardine (Sardina pilchardus) in the Central Mediterranean Sea has never been published within rigorous peer review process. In the past, stock assessment working groups in the Mediterranean requested such information; however, the size at which $50 \%$ of the fish population reaches the sexual maturity $\left(L_{50}\right)$ often received weak estimates based on a single or few years of observation, which do not necessarily reflect the whole stock. To address this data gap for the Central Mediterranean Sea, the present research estimated size at maturity of European sardine in the Strait of Sicily. In the study period (2009-2017), sampled individuals exhibited significant differences in size range as well as in body condition and reproductive effort. Data also permitted a clear identification of the spawning season, starting in September-October and ending in March-April the following year. Along the analyzed period, the size at first maturity ranged from 108 to $124 \mathrm{~mm}$ (total length) for females and from 102 to $122 \mathrm{~mm}$ for males. Significant differences were recorded among genders and years. Moreover, a goodness-of-fit measure was proposed to assess the robustness and reliability of $L_{50}$ estimates, and thus selecting those that minimize the fitting-associated errors. Finally, results suggested that the low proportion of immature individuals in the samples represents the main source of bias in $L_{50}$ estimation and possible solution was also proposed.

Keywords: size at first maturity, gonadosomatic index, condition factor, Strait of Sicily, spawning season and peak

\section{INTRODUCTION}

Small pelagic species comprise about one quarter of the global catch of fishes, such that they are both economically and ecologically considerable (Lleonart and Maynou, 2003; Ganias, 2014). Among these species, the European sardine, Sardina pilchardus (Walbaum, 1792), plays a key role in maintaining ecological processes in marine systems, occupying an essential intermediate trophic level in pelagic ecosystems (Bakun, 2006; Rumolo et al., 2016). European sardine (ES) belongs to the Clupeidae family, inhabiting from the North Sea to Senegal in the Atlantic waters, as well as in the 
Mediterranean Sea (Parrish et al., 1989). ES is a schooling fish, usually inhabiting the continental shelf (Iglesias et al., 2003; D'Elia et al., 2014), whose landings account for 15\% (more than 185,000 tons) of the total production of the Mediterranean Sea between 2016 and 2018 (FAO, 2020). ES is a multiple batch spawner with continuous development of gametes, showing a protracted spawning period with early maturation and high fecundity across most of the distribution range (Zwolinski et al., 2001; Somarakis et al., 2004; Silva et al., 2006; Sinovčić et al., 2008; Ganias, 2009), also displaying a high variability in terms of its recruitment, biomass, and distribution, mostly dependent on environmental and climatic conditions (LluchBelda et al., 1989; Schwartzlose et al., 1999; Ganias, 2009; Katara et al., 2011; Bonanno et al., 2016). Moreover, as a likely income breeder (i.e., animals for which energy intake for reproduction depends on feeding during the spawning season), environmental variability may determine the interannual variability of size at maturity by the availability of feeding resources (McBride et al., 2015). Unfortunately, this species, as other short-living fishes, displays fast growth, which can largely impact the maturation schedule according to stored energy and the way the energy is allocated between growth and reproduction, prior and along the spawning season (McBride et al., 2015). Variation in size- and age-at-maturity has a direct implication on productivity fluctuations in many fish populations, with implications for fisheries management (Morgan, 2018). For these reasons, a yearly-based evaluation of these populations is carried out routinely by stock assessment working groups within Mediterranean, Black Sea, and Atlantic waters [General Fishery Commission for the Mediterranean and Black Sea (GFCM); International Council for the Exploration of the Sea (ICES)].

Life history parameters, and particularly reproductive traits, are the basis for assessing population productivity and resilience, making them basic information for stock management. The estimate of the length at which $50 \%$ of the population appears sexually mature $\left(\mathrm{L}_{50}\right)$ is mainly used to define the minimum landing legal size for the exploited populations, although the $\mathrm{L}_{50}$ diverges to the minimum size at maturity, also in species maturing early (old age 0 and young age 1) like sardine (Amenzoui et al., 2006; Sinovčić et al., 2008).

Despite the relevance of this resource (ICES, 2019; SAC, 2019), only a few studies focused on length at maturity of ES population in the Mediterranean Sea, namely in the eastern Iberian waters (Silva et al., 2006) and in the Aegean waters (Tsikliras and Koutrakis, 2013). In the central Mediterranean waters only a study from North Adriatic Sea is available in the literature (Sinovčić et al., 2008). However, old parameters may no longer be appropriate given the likelihood that life history traits are adaptive and may change in response to changing environmental conditions or to evolutionary responses (Kjesbu and Witthames, 2007; Gordo et al., 2008; McBride et al., 2013; Ganias et al., 2015). Among others, gonad maturation and extension of reproductive season depend on both the genetic features and environmental influences, as geographic and/or reproductive isolation, temperature, and food availability (Begg et al., 2005; Sinovčić et al., 2008). Fishes displayed the ability to grow and mature at smaller sizes at low latitudes than the same species at higher latitudes, suggesting fish ability to adapt to wide patterns of environmental conditions (Ferreri et al., 2019). Furthermore, in the overexploited stocks a decrease in size and age at maturity was observed, highlighting the importance of these estimates as potential indicators for the effects of fisheries (Olsen et al., 2004; Lappalainen et al., 2016). New or improved estimates of maturity ogives should assist with sustainable management of living marine resources in both data-poor and datarich situations.

In the above-mentioned context, the present study using a 9-years-long time series obtained within the European Data Collection Framework (DCF; EC 665/2008) provided basic knowledge on the reproductive biology and its seasonal variability for the ES in the Central Mediterranean Sea. Moreover, length at sexual maturity of the sardine stock was estimated for each year and gender, to provide valid reference points for the assessment models as well as for the definition of management measures, as the minimum legal landing size.

\section{MATERIALS AND METHODS}

\section{Sampling}

Sardine in Geographical Sub-Area 16 [GSA 16, i.e., the Strait of Sicily, defined according to the Mediterranean sub-areas adopted for stock assessments by the GFCM (2009)] are targeted by purse seine and mid-water pelagic trawls. The sampling is of a stratified nature in that the fishing vessels of the fleet are divided into homogenous groups, based on four stratification variables (landings, length classes, geographical subregions, fleet segments), and independent samples are taken from each of these clusters. The advantage of using two different fishing techniques allowed to obtain both a wider size range of samples and a wider spatial coverage of the distribution ground of this species. Moreover, the movement behavior of the purse seine fleet along the year allows to retrieve more offshore samples than the other mid-water coastal trawling (Basilone et al., 2004). Most of the fishing activities are concentrated in the central part of the study area (Figure 1), where larger part of the population is located (Barra et al., 2015; Bonanno et al., 2015). During autumn and winter, the fully recruited sardine population is known to show migratory behavior for spawning purposes (Morello and Arneri, 2009; Ganias and Nunes, 2011). This expansion most likely reflects the peculiarities of the Mediterranean Sea, where suitable areas favoring growth, feeding, and spawning processes for small pelagic populations tend to be localized (Basilone et al., 2017). The existence of such limited suitable areas along with complex oceanographic and topographic characteristics (i.e., irregularities in the coastline and the bathymetry) is likely to prevent long-distance migration for sardine between spawning and juvenile grounds (Giannoulaki et al., 2011). This is even more pronounced in the Strait of Sicily, where no significant seasonal variation was shown (Barra et al., 2015). Therefore biological sampling from coastal (mid-water trawling covered) to more offshore waters (purse seining covered) could be considered representative of most part of the population, including the 


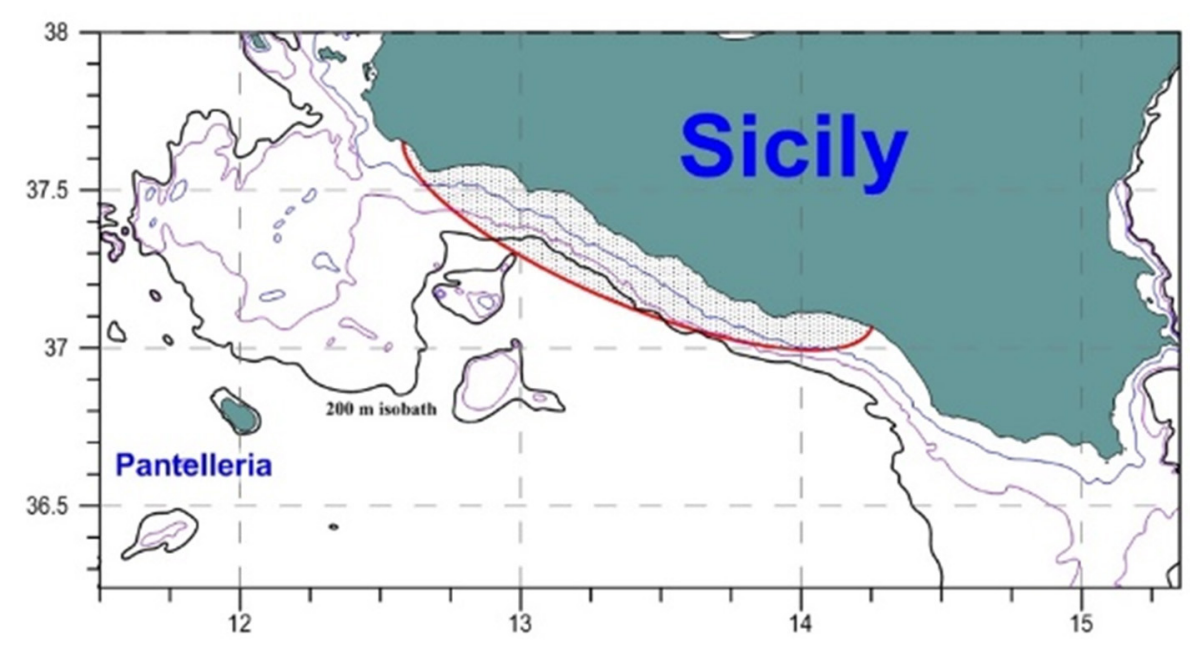

FIGURE 1 | Map of the study area with the main fishing ground located in the shadowed sector, according to Basilone et al. (2004). Isobaths of $50 \mathrm{~m}$, 100 m, and $200 \mathrm{~m}$ (black line).

most spawning fraction in winter (Ganias et al., 2007). Along 9 years (2009-2017), monthly random samples of ES were collected from commercial landings in the Strait of Sicily area (Figure 1).

At the laboratory, individuals were sexed and analyzed for total body length (TL) to nearest $1 \mathrm{~mm}$, total weight (TW) somatic weight (i.e., the gonad-free body weight; SW) to nearest $0.1 \mathrm{~g}$, and gonadic weight $(\mathrm{GW})$ to nearest $0.01 \mathrm{~g}$. Along 9 years, a total amount of 14916 ES was sexed (7221 females and 7195 males) and reproductive information collected. Monthly samples ranged between a minimum of 354 in January to 3266 in September (Table 1) and the number of monthly samples varied among years, but January appears the most-often under-sampled month. However, the total amount of sampled fish showed a relevant decrease only in 2016 and 2017. No use of live animals has been required for this study and no specific permissions were needed for the sampling activities in all of the investigated areas, because the target species is commercially harvested (neither endangered nor protected) and it was caught in areas where fishing is allowed.

Gonad maturity was macroscopically determined, and development stages were assigned by means of a six-class scale for the identification of reproductive phase. This scale, proposed by the international scientific community within the context of the ICES, is particularly developed for sardine and anchovy, that is, small pelagic species with asynchronous gonad development and indeterminate fecundity (ICES, 2008). According to the agreed international protocol (ICES, 2008), the six phases are: (1) immature; (2) developing; (3) imminent spawning; (4) spawning; (5) partial post-spawning; and (6) spent. Phase 1 was considered immature (spawning not imminent this year) and phases 2-6 were considered mature (they have contributed or are contributing to the reproduction of the year).

\section{Reproduction}

Many studies have employed condition indices to understand fish population health and variability (Lloret et al., 2012; Thorson, 2015; Brosset et al., 2017). Body condition is a way to measure the amount of stored energy in the body and reflects a set of biotic (e.g., food availability, parasitic infections, physiology) and abiotic (e.g., physical conditions) factors experienced by individuals over a period of their life (Vila-Gispert and MorenoAmich, 2001; Lloret et al., 2002).

In order to evaluate the existence of differences in body size between genders, an ANCOVA test was carried out on log-transformed data of TL and SW $(F=98.36$; $p<0.001)$. According to these results, all the following analyses were carried out for separated genders.

The relative somatic condition factor $\left(K_{n}\right)$ of individuals was estimated as follows (Le Cren, 1951):

$$
K_{n}=\frac{S W}{a T L^{b}}
$$

where $a$ and $b$ are the parameters of the length-weight regression (i.e., TL vs. SW), SW is the somatic weight (g), and TL is the total fish length $(\mathrm{mm})$. Somatic, rather than total, weight is used to avoid variability due to the maturity stage. For $K_{n}$ computation the length-weight regression power model coefficients were estimated for each gender separately: $a=0.0042$ and $b=3.2237$ $\left(r^{2}=0.89\right)$ for females, and $a=0.0025$ and $b=3.4105\left(r^{2}=\right.$ $0.8557)$ for males.

Energy allocated to reproductive growth (i.e., reproductive investment) was estimated by the gonadosomatic index (GSI):

$$
\mathrm{GSI}=\mathrm{GW} / \mathrm{SW}^{*} 100
$$

where GW is gonadic weight (g) and SW is somatic weight (g) (DeVlaming et al., 1982). 
TABLE 1 | Number of European sardine sampled $(n)$ for each gender (i.e., female $[\mathrm{F}]$ and male $[\mathrm{M}]$ ) along the study period, by year and month.

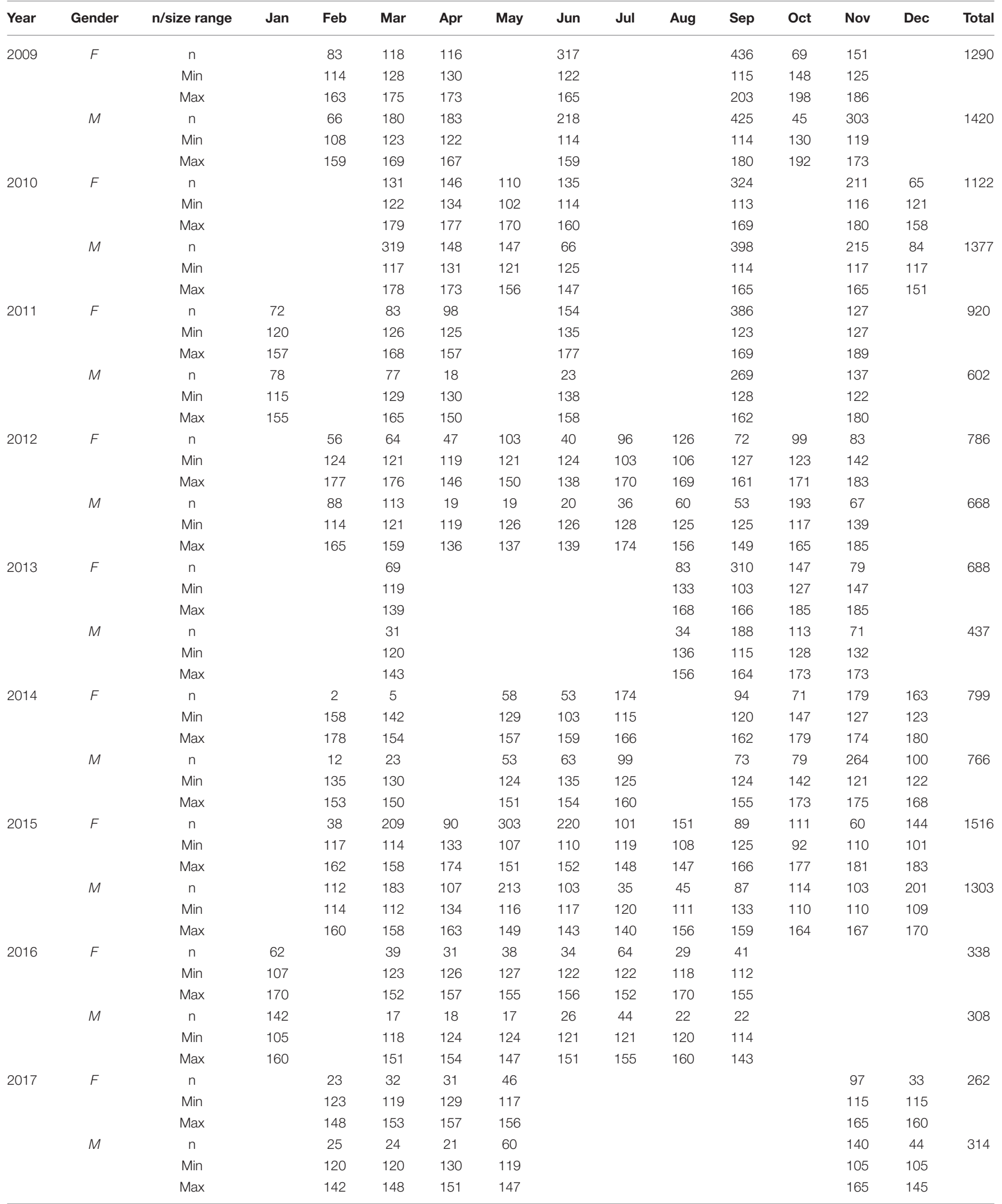

The minimum (Min) and maximum (Max) total length ( $\mathrm{mm}$ ) were also provided to evaluate the size range for each subset. 


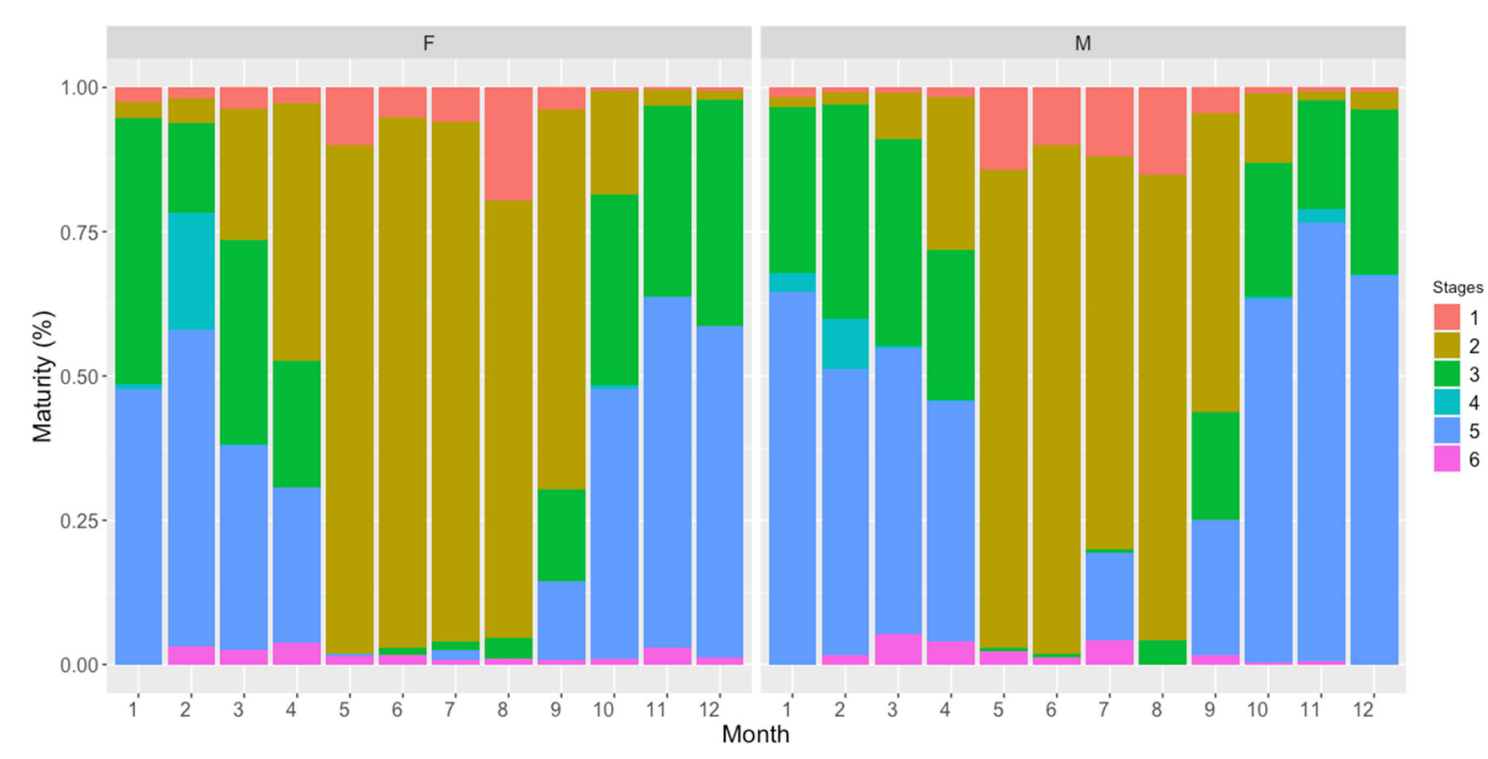

FIGURE 2 | Monthly evolution of gonadic maturity stages pooling the whole study period for female (F) and male (M) European sardine.

A logistic model was applied to fit size at maturity data for estimating the length at which the $50 \%$ of the population appears sexually mature $\left(L_{50}\right)$, as indicated by the inflection point of the ogive. Fitted data belong to the spawning season (September-March; see Results section for more details) of sardine as determined by the gonadosomatic and condition indices monthly evolution:

$$
P_{i}=\left(1+e^{-\left(\alpha+\beta x_{i}\right)}\right)^{-1}
$$

where, $P_{i}$ is the probability of being mature at size $x_{i}$, and $\alpha$ and $\beta$ are model parameters representing the intercept and slope of a linear form of this model; then, based on estimated parameters, $\mathrm{L}_{50}$ is computed as: $\mathrm{L}_{50}=-\alpha / \beta$.

To investigate the existence of differences in $\mathrm{L}_{50}$ between genders, the ogives were computed per separate genders but the analyses were carried out also by pooling males and females together by year, to evaluate if increasing the number of observations would benefit to the goodness of fitting.

Although there is no commonly accepted agreement on how to assess the fit of a logistic regression, there are some approaches. The goodness of fit of the logistic regression model can be expressed by some variants of pseudo-r $r$ squared statistics $\left(\right.$ Pseudo- $\left.{ }^{2}\right)$, most of which being based on the deviance of the model (Ferreri et al., 2016). Therefore, in order to compare the goodness of fit among obtained maturity ogives, the McFadden's $r^{2}$, based on the log-likelihood kernels for the interceptonly model and the full estimated model has been adopted (McFadden, 1974). Furthermore, the graphical representation of ogive fitting with their confidence curves and the bins of mature/immature individuals plotted along the axis allowed more detailed evaluation of each fitting ogive.
The analyses were performed in the R statistical environment ( $\mathrm{R}$ Core Team, 2018), using the "sizeMat" package for maturity ogive estimates (Torrejon-Magallanes, 2020). Areaspecific maturity ogives are presented with $95 \%$ confidence intervals for the predicted probability, which were determined by bootstrapping 1,000 times (see Ferreri et al., 2019, for more details).

\section{RESULTS}

\section{Reproductive Cycle and Body Conditions}

The monthly proportion of mature stages along the year showed that stage 2 individuals (developing oocytes, which will be spawned within the year) mainly dominated the samples between May and September, while most advanced maturity stages (36) were concentrated mainly from October to April (Figure 2). Moreover, the pattern in spawning seasonality was similar between genders, further supporting the period between October and March/April as the spawning period for both genders.

Monthly GSI, based on the pooled data along the whole study period, confirmed a 7-month spawning season extension, between September and March, as also supported by the lower $K_{n}$ along these months (Figure 3). Although both genders displayed a similar pattern, the monthly GSI showed higher average values in females, especially during the spawning peak (January-February).

\section{Length at Maturity}

The $\mathrm{L}_{50}$ estimations were obtained by selecting data from the spawning period as determined by reproductive indices and maturity monthly patterns (September-March), separately for gender and year together with an $r^{2}$ statistic to evaluate the goodness of fit. Along the study period, $\mathrm{L}_{50}$ estimations were 


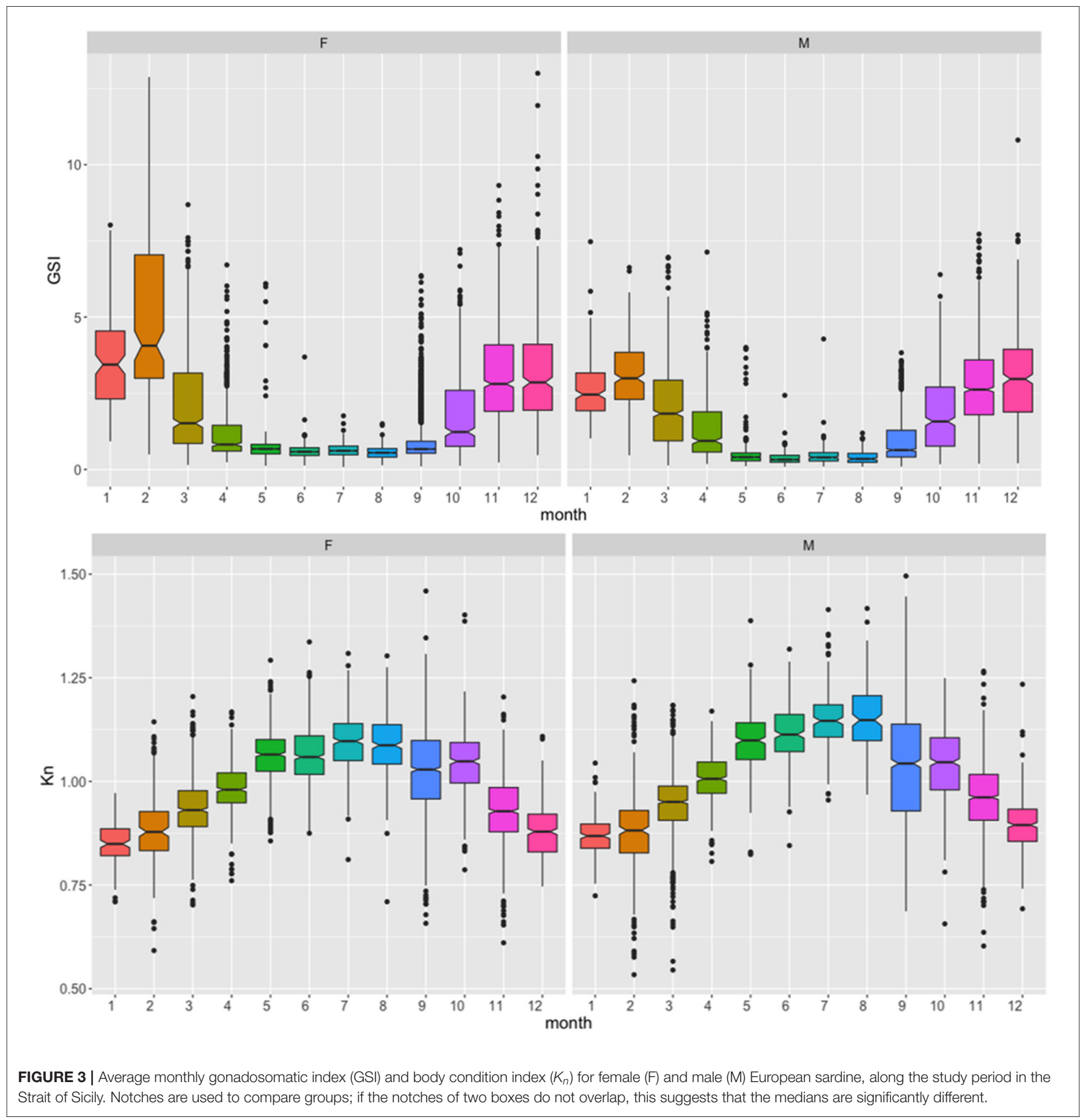

higher in females, with values ranging between $114( \pm 1.1) \mathrm{mm}$ and $126( \pm 0.8) \mathrm{mm}$, than in males, $\mathrm{L}_{50}$ between $102( \pm 5.7)$ $\mathrm{mm}$ and $122( \pm 1.4) \mathrm{mm}$, the latter displaying wider confidence intervals and reduced Pseudo- $r^{2}$ values (Table 2). Confidence intervals denoted significant differences between females and males almost over the whole period (Figure 4).

However, within each gender, the $\mathrm{L}_{50}$ estimations showed very similar values along most part of the study period (Figure 4). In females, $L_{50}$ values could be split into two groups: the higher between 121 and $126 \mathrm{~mm}(2009,2012,2013,2014,2016)$ and the lower between $114 \mathrm{~mm}$ and $117 \mathrm{~mm}$ (2010, 2011, 2015, 2017); while in males the two $\mathrm{L}_{50}$ groups were less evident than in females, since the wider confidence intervals make the separation difficult, particularly in 2011 and 2016 (Figure 5).

In females, the higher Pseudo- $r^{2}$ values identified the best model fitting for most of the sampling years (2009, 2012-2014, and 2016), which showed also the higher $\mathrm{L}_{50}$ values; while nonoptimal fittings were advisable in 2011 and 2017 (Table 2). The 
TABLE 2 | Length at maturity $\left(L_{50}\right)$ estimations for separated genders, for each year.

\begin{tabular}{|c|c|c|c|c|c|c|c|c|c|c|c|c|}
\hline Year & Females $\mathrm{L}_{50}(\mathrm{Cl})(\mathrm{mm})$ & Intercept & Slope & Ps-r ${ }^{2}$ & Males $\mathrm{L}_{50}(\mathrm{Cl})(\mathrm{mm})$ & Intercept & Slope & Ps- $r^{2}$ & Overall $\mathrm{L}_{50}(\mathrm{Cl})(\mathrm{mm})$ & Intercept & Slope & Ps-r $r^{2}$ \\
\hline 2009 & $121(0.7)$ & -38.86 & 0.32 & 0.52 & $112(2.3)$ & -13.70 & 0.12 & 0.15 & $117(1.0)$ & -20.04 & 0.17 & 0.26 \\
\hline 2010 & $117(1.0)$ & -39.67 & 0.33 & 0.35 & $110(2.1)$ & -23.04 & 0.20 & 0.18 & $113(1.1)$ & -24.79 & 0.21 & 0.22 \\
\hline 2011 & 115 (3.3) & -19.32 & 0.16 & 0.25 & $107(5.7)$ & -14.63 & 0.13 & 0.17 & $119(2.0)$ & -10.52 & 0.08 & 0.10 \\
\hline 2012 & $121(1.8)$ & -35.52 & 0.29 & 0.46 & 114 (3.0) & -29.09 & 0.25 & 0.34 & $126(0.5)$ & -27.76 & 0.22 & 0.39 \\
\hline 2013 & $124(0.5)$ & -44.43 & 0.36 & 0.59 & $122(1.4)$ & -32.82 & 0.26 & 0.40 & $130(0.4)$ & -27.30 & 0.20 & 0.46 \\
\hline 2014 & $126(0.8)$ & -59.43 & 0.47 & 0.62 & $117(2.6)$ & -27.80 & 0.24 & 0.34 & $138(0.5)$ & -15.12 & 0.11 & 0.17 \\
\hline 2015 & $114(1.1)$ & -28.53 & 0.25 & 0.46 & $108(2.0)$ & -14.76 & 0.14 & 0.22 & $114(0.9)$ & -14.93 & 0.13 & 0.25 \\
\hline 2016 & 123 (1.6) & -19.03 & 0.15 & 0.39 & $102(5.7)$ & -7.41 & 0.07 & 0.11 & $115(2.0)$ & -10.17 & 0.08 & 0.17 \\
\hline 2017 & $117(3.8)$ & -11.97 & 0.10 & 0.14 & 110 (3.8) & -8.56 & 0.07 & 0.11 & $112(2.8)$ & -9.26 & 0.08 & 0.12 \\
\hline
\end{tabular}

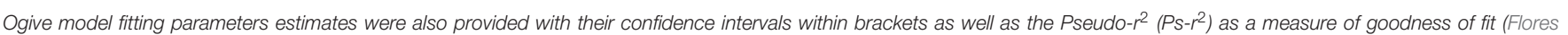
et al., 2019).

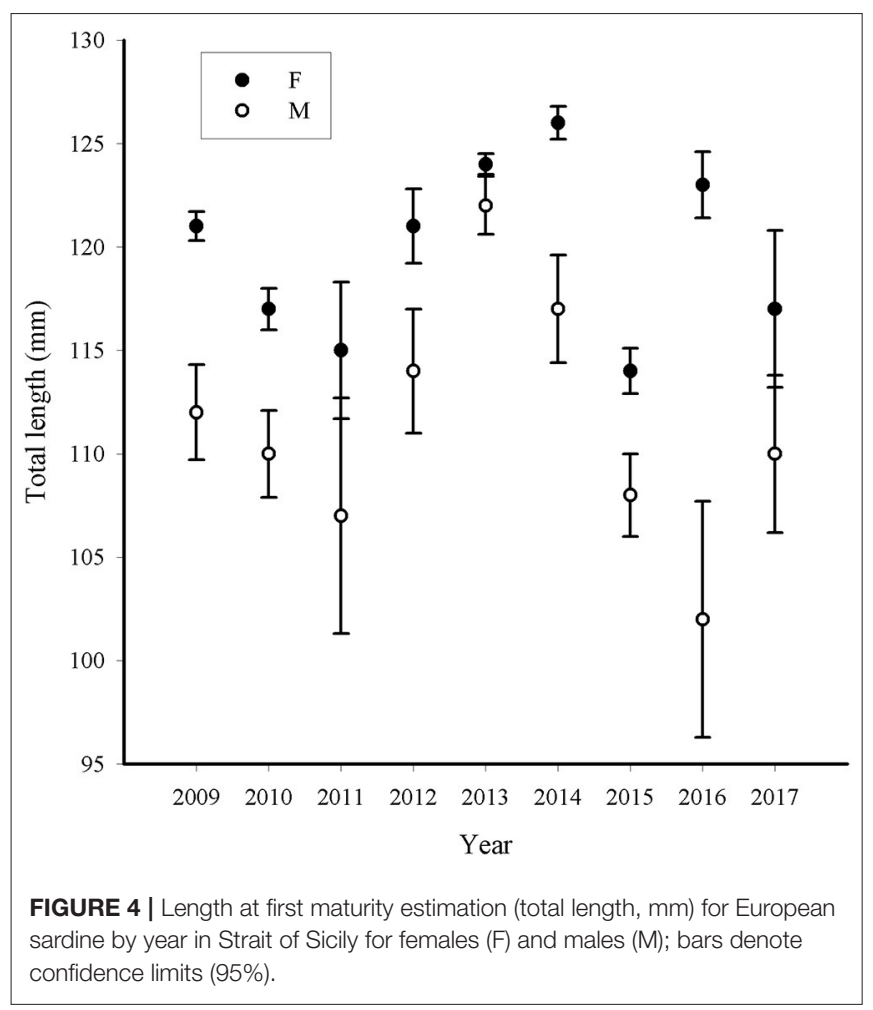

Pseudo- $r^{2}$ values were generally lower in males than in females and particularly in 2016 and 2017, but also the period 20092011 displayed estimates below 0.20 value (Table 2). In males, the analyses that minimize error and improve fitting (i.e., with higher Pseudo- $r^{2}$ values) were obtained between 2012 and 2014, with $\mathrm{L}_{50}$ ranging between $117 \mathrm{~mm}$ and $122 \mathrm{~mm}$ (Table 2). The Pseudo- $r^{2}$ values for ogives of pooled genders presented lower values than those for females, but better than Pseudo- $r^{2}$ on males except in 2011 and 2017 (Table 2).

The visual inspection of ogive graphs displayed thinner confidence intervals for combined genders than separated ones (Figure 5), although the pooled genders not always increased the goodness of fitting, as indicated by the Pseudo- $r^{2}$ (Table 2).
However, the ogive plots highlighted that years with wider confidence intervals were linked to the poor number of immature specimens, especially in the lower size classes (Figure 5). Finally, a plot of Pseudo- $r^{2}$ vs. $\mathrm{L}_{50}$ was provided to identify the best $\mathrm{L}_{50}$ estimation among years (Figure 6, left panel). This plot showed the length at maturity separately estimated per each year and gender have major accuracy and precision (Figure 6). Such a plot highlights how fittings of maturity ogive improved reaching more robust estimation at values of $\mathrm{L}_{50}$ around $125 \mathrm{~mm}$ (Pseudo- $r^{2}>$ 0.5) (Figure 6, left panel).

\section{DISCUSSION}

In multiple-spawning fishes, specifically those with asynchronous gonadic development, such as sardine, macroscopic determination of spawning phase is difficult without the support of microscopic examination; this is due to its subjectivity and variability, which represent a source of bias particularly relevant in discriminating immature from mature individuals (Costa, 2009; Ferreri et al., 2009; Khoufi et al., 2014). Nonetheless, macroscopic evaluation of gonads is widely adopted in the fishery resources assessment, because it allows examining a wider number of fishes (Ferreri et al., 2009; Basilone et al., 2015). Achieving a wide range of immature and mature sizes can also be an obstacle when data only came from commercial fisheries (Bromley, 2003), particularly for small fishes that may reach the recruitment size to fishery at about the same length than first maturity. To reduce this important source of bias, the ogive model may be also fitted by pooling the data sets of both genders, particularly when used for assessment purposes (ICES, 2010).

The estimation of the spawning seasonality from somatic and gonadic condition indices agrees with observations of monthly maturity status further supporting the timing and duration of ES spawning in the Strait of Sicily, which occurred from September to March the following year, in agreement with past studies across the Mediterranean (Tsikliras et al., 2010). Despite its wide use, the validity of GSI has often been questioned because of the possible ovarian growth allometry, and it has generally been recommended that this index should not be used without proper validation (DeVlaming 

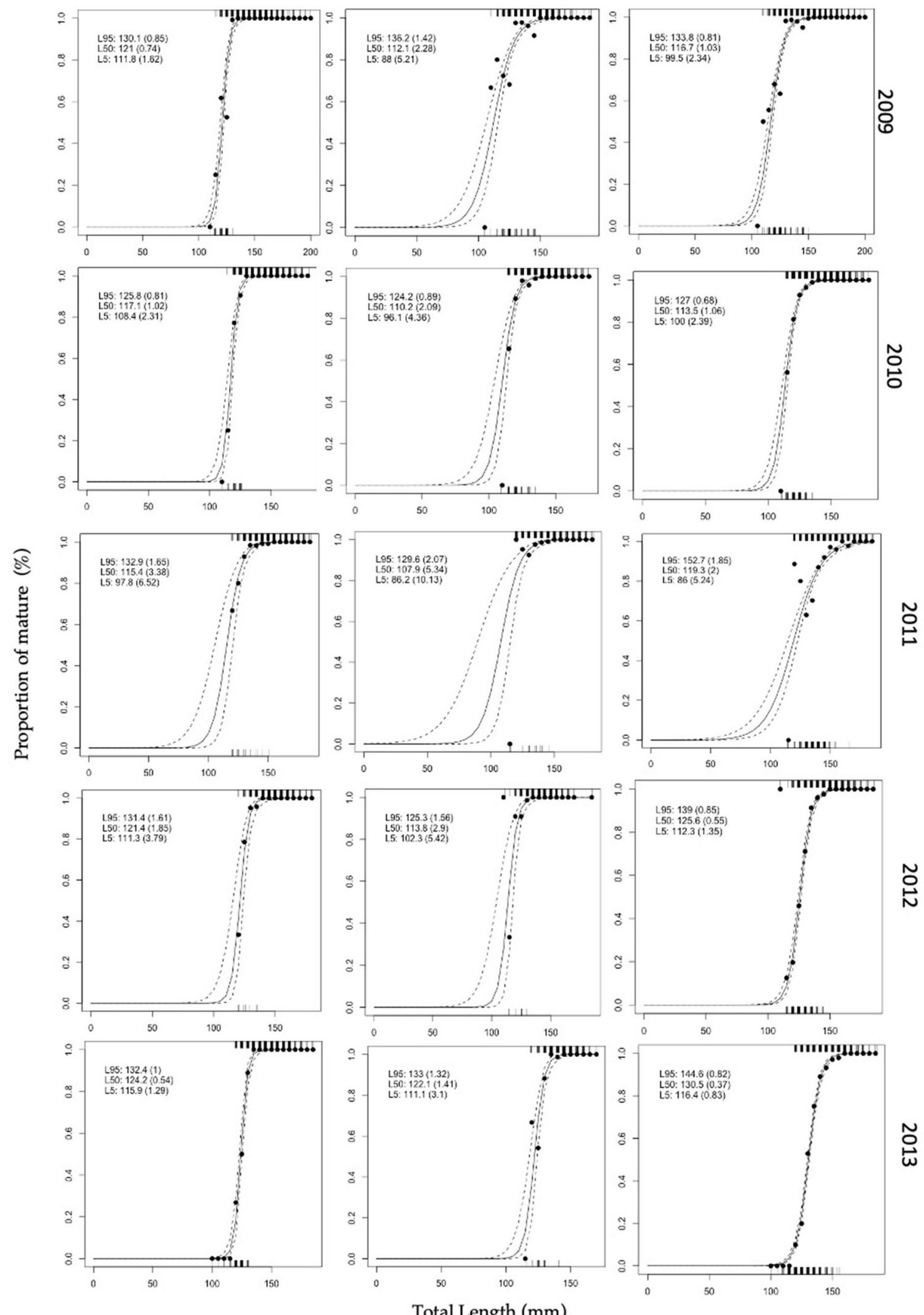

FIGURE 5 | Continued 

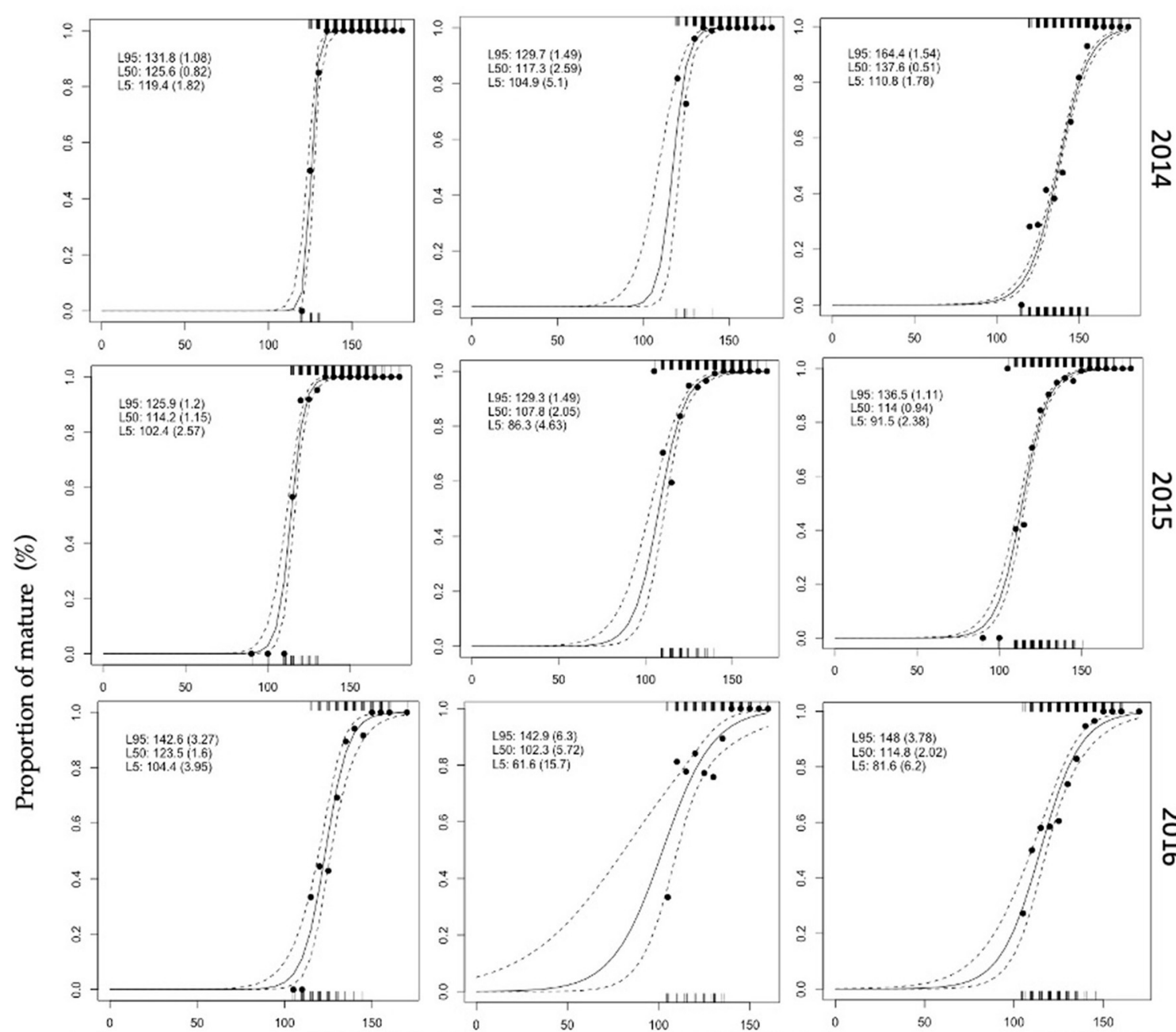

苍
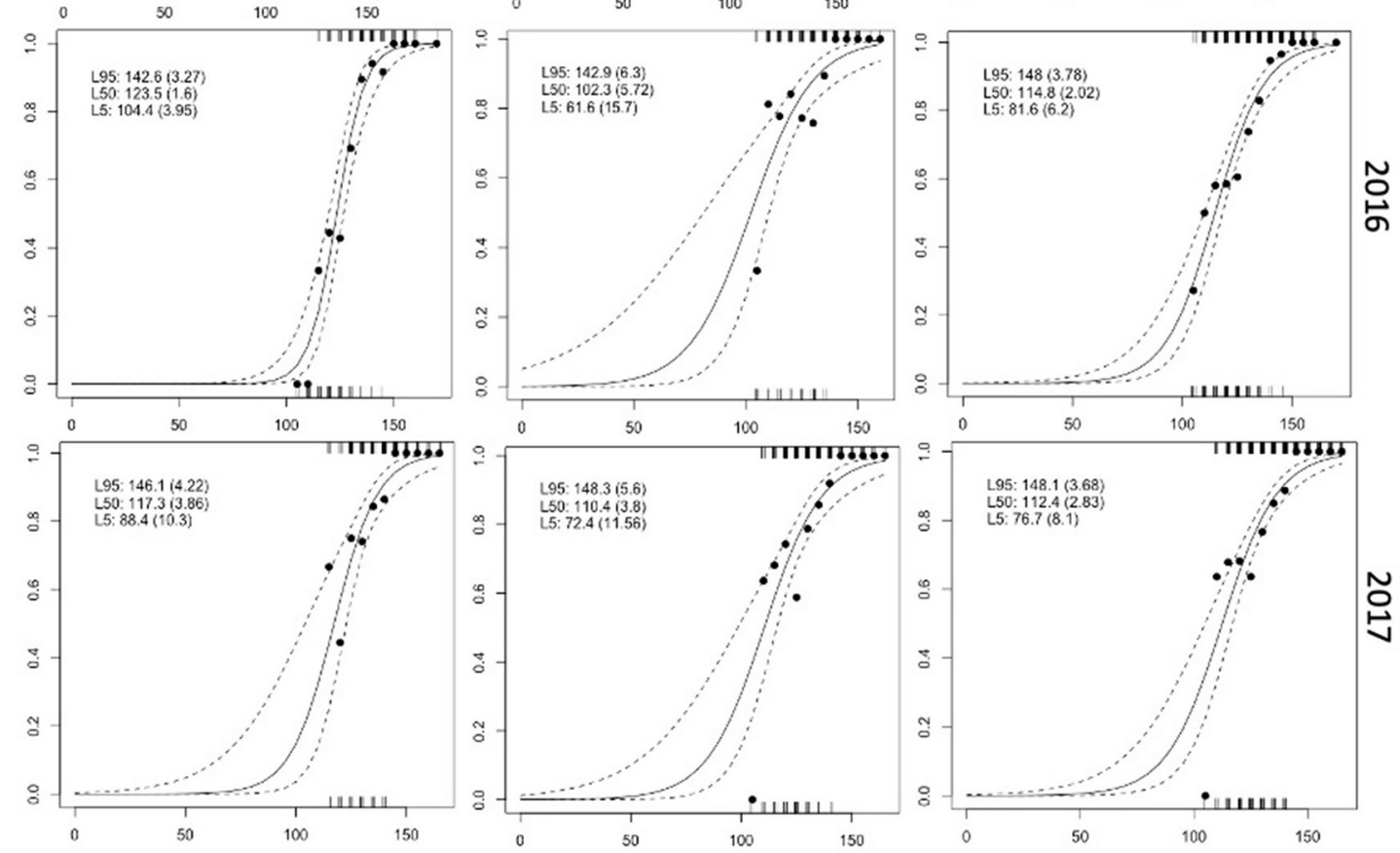

Total Length $(\mathrm{mm})$

FIGURE 5 | Maturity ogives for European sardine in the Strait of Sicily per year, from 2009 to 2017 for females (left panels) males (middle panels) and overall (right panels). Solid line is the predicted proportions of mature ES at length, the dashed lines denote the 95\% confidence curves, and the tick marks on the bottom and top axes indicate the immature and mature ES recorded, respectively. The proportion of mature for each bin are also reported (black, filled circles). The point estimates for mean size $(+95 \% \mathrm{CL})$ are also provided for $5 \%\left(\mathrm{~L}_{5}\right), 50 \%\left(\mathrm{~L}_{50}\right)$, and $95 \%\left(\mathrm{~L}_{95}\right)$ mature individuals. See Table 2 for more details about the logistic equation parameters for each year.

et al., 1982). However, the isometric ovarian growth in the Mediterranean sardine has been attributed to the lack of a size-dependent effects (Somarakis et al., 2004). These authors further strengthen the appropriateness of the GSI index for the Mediterranean populations of ES, since they observed that fish length, geographical region, month of capture, and fat stage 

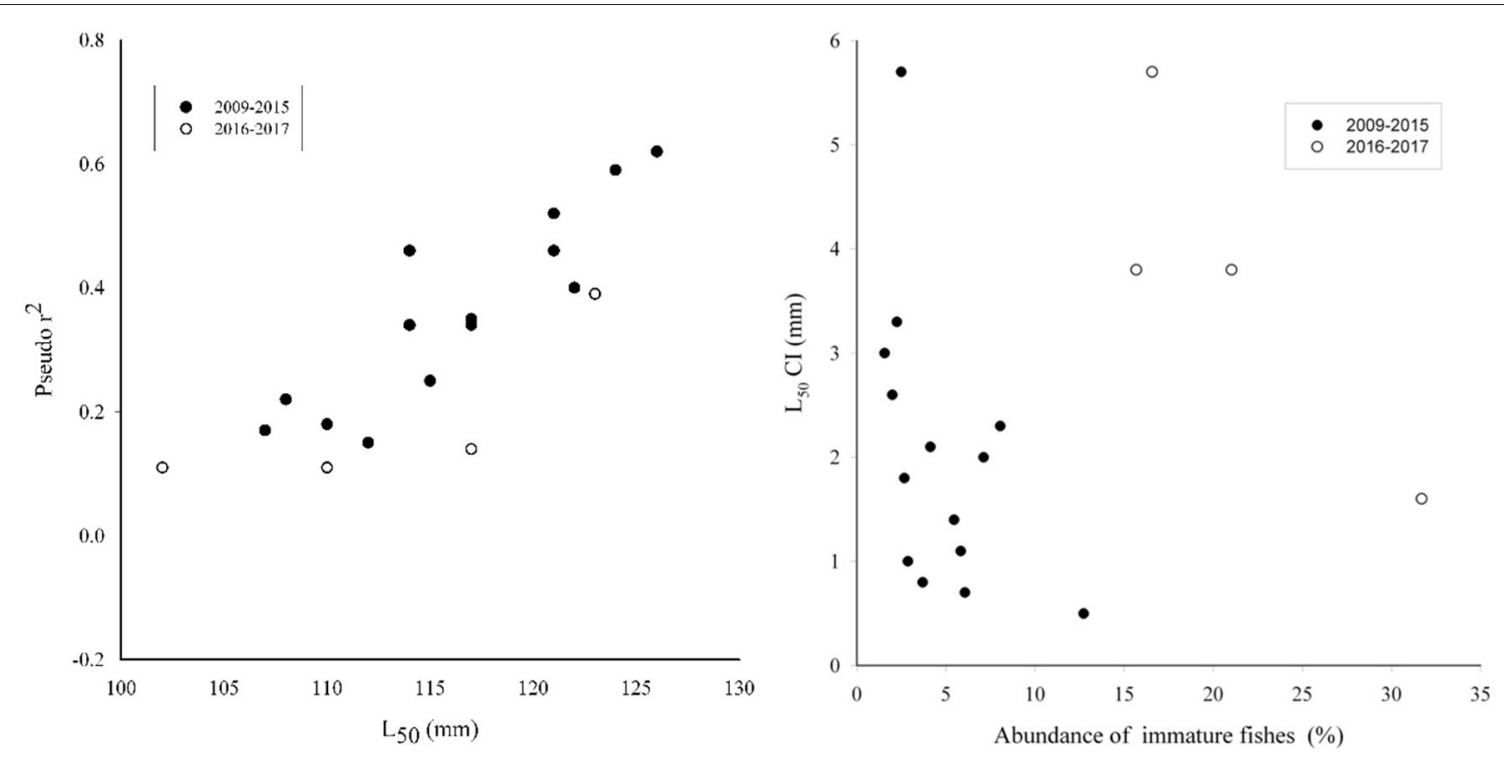

FIGURE 6 | Scatterplot of length at first maturity $\left(L_{50}, \mathrm{~mm}\right)$ vs. corresponding Pseudo- ${ }^{2}$ and the scatterplot of confidence intervals ( $L_{50} \mathrm{Cl}$, mm) of the ogive fitting vs. the corresponding abundance of immature fishes by year (right panel). Data from male and female European sardine were plotted separately, but black and white dots were used to distinguish two different study period (2009-2015 and 2016-2017) according to the legend.

had no effect on GSI, at least for females (Somarakis et al., 2004).

The evolution of monthly body condition index showed a complementary trend to GSI, indeed $K_{n}$ displayed minima in January and December and maxima in July-August, when it is expected that the whole energy budget incoming from feeding would be devoted to somatic growth than gonadic (McBride et al., 2015). The males displayed lower body conditions than females at the spawning peak, supporting the main role of females that spend more energy than males in the gamete production along the season, and then a slower recovery of body condition (McBride et al., 2015).

The spawning period of European sardine displays variability in extension among different areas, although it is generally protracted from autumn to spring, both in the Atlantic and Mediterranean waters (Table 3). As in the study area, the spawning season lasting at least for 6 months with a peak in winter, except in the Adriatic Sea and Morocco waters (Table 3), where an inter-annual variability was recorded at least in monthly evolution of gonadic maturity stages (Amenzoui et al., 2006).

The present $\mathrm{L}_{50}$ results may appear divergent compared with previous studies on ES, especially from populations inhabiting in Atlantic areas; however, size at maturity estimates in the study area are in agreement with previous observations in the Mediterranean Sea (Table 3). Particularly, values recorded from the Aegean Sea are very similar (Tsikliras and Koutrakis, 2013); moreover, such similarity seems confirmed over time since results from the Strait of Sicily were also in agreement with Aegean Sea $\mathrm{L}_{50}$ in the 1990s as well as in western Mediterranean (Table 3). However, a huge discrepancy is notable with the Adriatic waters, where the $\mathrm{L}_{50}$ values, lower than all the other evaluations in both Atlantic and Mediterranean (Table 3), may be linked to the oligotrophic condition occurring in this area (Zavatarelli et al., 1998), since the amount of available food influences the sexual maturation (McBride et al., 2015). In the Mediterranean basin (Sinovčić et al., 2008; Tsikliras and Koutrakis, 2013) as well as in the present research, the ES appeared to reach maturity at a lower size in male than in female (Table 3), as also observed in other small pelagic species (Pešić et al., 2013).

Along the study period, the inter-annual variability in $\mathrm{L}_{50}$ was observed to be resumed into two main levels, a higher and a lower level, at least for females (Figure 4). Within such estimates, the former group was more robust, as suggested by the higher Pseudo- $r^{2}$ as well as by the thinner confidence intervals. The plot of Pseudo- $r^{2} v s$. the $\mathrm{L}_{50}$ estimates highlights more robust ogives at values of $\mathrm{L}_{50}$ around $125 \mathrm{~mm}$ (Figure 6, left panel). This plot also displayed a discrepancy between the time series 2009-2015 and the latter two years 2016 and 2017, which appear with lower Pseudo- $r^{2}$ values despite variability in $\mathrm{L}_{50}$ estimates. Indeed, in these two years, the samples were scarce compared with those of previous years, and such reduced sampling effort may affect bias associated to the $\mathrm{L}_{50}$ evaluations, as suggested by the plot of the $\mathrm{L}_{50}$ confidence intervals $v$. the proportion of immature ES sampled per year (Figure 6, right panel). In particular, higher accuracy (low CI values) was observed when the proportion of immature individuals increased. However, the years 2016 and 2017 displayed lower accuracy, despite the higher proportion of immature specimens (Figure 6, right panel). Indeed, the observed variability in the monthly sampling per year as well as the number of fishes analyzed may appear as a potential source of bias in the $\mathrm{L}_{50}$ ogive fitting as observed in 2016 and 2017, when the total amount of individuals was considerably lower than in the previous years (Table 1). 
TABLE 3 | Literature values of size at maturity of European sardine estimated in the Mediterranean Sea and Atlantic Ocean.

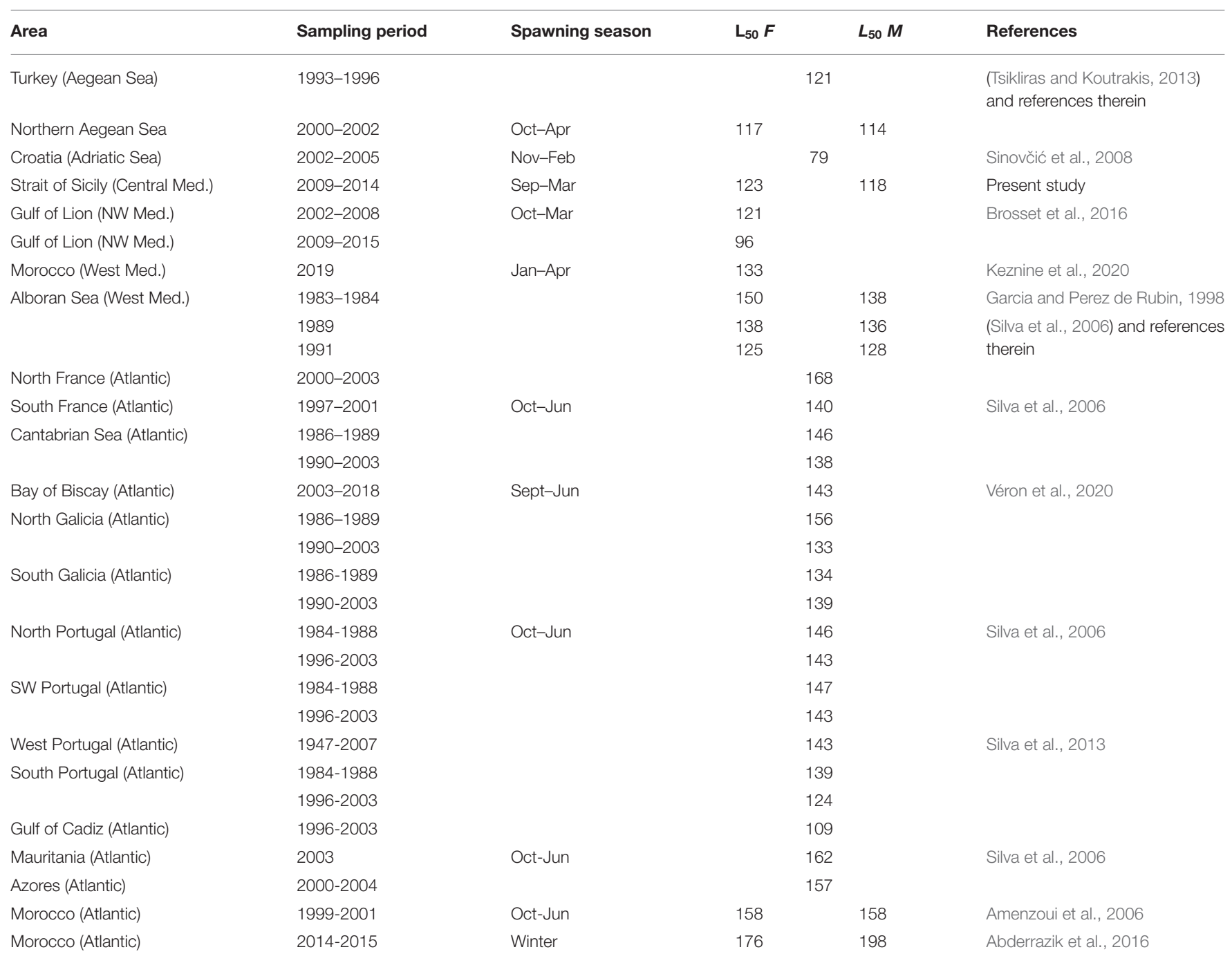

Length at maturity was reported for female $\left(L_{50} F\right)$ and male $\left(L_{50} M\right)$ separately, when available for separated genders. Stock is identified by sampling area; sampling period is in years;

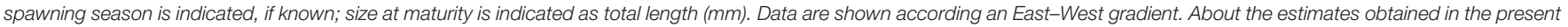
study, in the table the average values with higher accuracy and precision, obtained from years 2009, 2012-2014, and 2016 for females and $2012-2014$ for males were included.

In the analyzed time series, monthly sampling gaps should be detected especially between December and January, mainly due to fishing seasonal closure; also, gaps in July-August were often recorded. Such type of sampling gaps has been already indicated in the literature as important source of bias affecting the stock assessment parameters estimation for ES. In the eastern Mediterranean Sea, sampling gaps were also linked to the fishing season closure in December-February and to the high proportion of juveniles sampled during this period, which may inflate the age 1 class (Tsikliras and Koutrakis, 2013). Certainly, since $\mathrm{L}_{50}$ is preferably estimated by spawning season samples, monthly gaps should be avoided in this period, as observed in 2016 (Table 1). Furthermore, most of the immature fish is rejected directly on board after catch because they are found to be under the legal size; therefore the presence on board of independent observers should allow to obtain samples of adequate proportion of smaller individuals, which probably include the higher presence of immature fish.

Otherwise, the absence of trends in $\mathrm{L}_{50}$ as well as the observed variability among years in both genders would be linked to pelagic ecosystem flexibility. As in several pelagic fish species, maturity is linked to the environmental productivity (McBride et al., 2015), also in the case of sardine in both Atlantic and Mediterranean waters (Silva et al., 2006, 2013). Silva et al. (2013) postulated that an increase in temperature may induce in sardine a maturation at smaller length, and vice versa, and that higher temperatures improve body condition through increased feeding efficiency or a combination of both. Lower temperature associated with higher food availability within an upwelling system, which is common in the study area (Bonanno et al., 2014), was proved to enhance the condition, and consequently maturation of smaller individuals in different pelagic fish species 
(Parrish and Mallicoate, 1995; Watanabe and Yatsu, 2006). A wide research carried out in several Mediterranean areas, including the study area, described a decreasing trend in body condition as well in maximum length in sardine during the last decades (Brosset et al., 2017). These decreases are in agreement with other observations, such as reduction in biomass and biological state within the basin (Vasilakopoulos et al., 2014; Tsikliras et al., 2015). In the same period, fluctuations of sea surface temperature and chlorophyll concentration were observed along the whole Mediterranean Sea (Brosset et al., 2017), including the study area particularly from 2009 onward (Basilone et al., 2020). Variability in chlorophyll concentration, temperature, and food retention have been recognized as driven for phenotypic flexibility phenomena, which may determine changing the size at maturity (Wertheimer et al., 2004). Reduction in size and age at maturity have been reported for a large number of commercial fish species (Jørgensen et al., 2007; Kuparinen and Merilä, 2007) due to environmental variation, fishing intensity or a combination of both (Marshall and McAdam, 2007). Moreover, variation in size at maturity with latitude is a common feature among Clupeiformes in European waters (Ganias, 2014), as observed both in sardine (Silva et al., 2006) and anchovy (Huret et al., 2019).

\section{CONCLUSIONS}

The analysis of such time series permitted not only to give more robustness to the $\mathrm{L}_{50}$ estimates, but also to highlight gaps in the sampling program, which in some year heavily biased the $\mathrm{L}_{50}$ calculations. The main concern from the present study suggests to reduce as much as possible the gaps in monthly distribution of samples from the commercial vessels and, possibly, to increase the sampling on board, in order to record also possible fishes under minimum legal size discarded at sea. Moreover, the proper integration of scientific survey data into commercial sampling data would provide a wider samples coverage, improving stock assessment evaluations as well as more precise control rules (e.g., minimum legal size). Fish species should be caught only within a specific window of their size, with a lower size limit excluding the immature individuals and an upper size limit excluding fishes with the greatest reproductive potential (Coleman et al., 2000), since bigger size spawner guarantee a better recruitment (Marshall and Frank, 1999). Thus, a reduction

\section{REFERENCES}

Abderrazik, W., Baali, A., Schahrakane, Y., and Tazi, O. (2016). Study of reproduction of sardine, Sardina Pilchardus in the north of Atlantic Moroccan area. AACL Bioflux 9, 507-517.

Amenzoui, K., Ferhan-Tachinante, F., Yahyaoui, A., Kifani, S., and Mesfioui, A. H. (2006). Analysis of the cycle of reproduction of Sardina pilchardus (Walbaum, 1792) off the Moroccan Atlantic coast. Comptes Rendus Biol. 329, 892-901. doi: 10.1016/j.crvi.2006.08.002

Bakun, A. (2006). Fronts and eddies as key structures in the habitat of marine fish larvae: opportunity, adaptive response and competitive advantage. Sci. Mar. 70:105-122. doi: 10.3989/scimar.2006.70s 2105.

Barra, M., Petitgas, P., Bonanno, A., Somarakis, S., Woillez, M., Machias, A., et al. (2015). Interannual changes in biomass affect the spatial aggregations of in size at maturity would compromise reproductive potential as well as stock suitability levels. Therefore, new efforts would be devoted to better integrate the commercial and scientific surveys sampling programs, within the DCF. Recently, the European Court of Auditors pointed out how the European commission together with the Member States are responsible for the failure of the EU fishery policy in the Mediterranean Sea. In particular, they highlighted among others important factors that in the Mediterranean, where fisheries management is mostly linked to limits on fishing effort (and not catches), fishing rates were at twice sustainable levels, therefore encouraging Member States to increase the amount of funds related to conservation measures (European Court of Auditors Special Report, 2020).

\section{DATA AVAILABILITY STATEMENT}

The data analyzed in this study is subject to the following licenses/restrictions: Due to the data policy of the Research Project (Piano di lavoro Raccolta Dati Alieutici - REG. (UE) N. 508/2014 relativo al Fondo europeo per gli affari marittimi e la pesca (FEAMP) e REG. (EU) N. 2017/1004) the datasets analyzed in this article cannot be made publicly available. Requests to access these datasets should be directed to https://dcf-italia.cnr. it/web/\#/request-data.

\section{ETHICS STATEMENT}

No use of live animals has been required for this study and no specific permissions were needed for the sampling activities in all of the investigated areas, because the target species is commercially harvested (neither endangered nor protected) and it was caught in areas where fishing is allowed.

\section{AUTHOR CONTRIBUTIONS}

GB, RF, MP, and AG: data curation. $\mathrm{MB}$ and GB: formal analysis and validation. $\mathrm{AB}$ : funding acquisition and project administration. RF and GB: investigation, methodology, and writing-original draft. SA, IF, and GG: software. GB: supervision. $\mathrm{SM}, \mathrm{MB}, \mathrm{SA}, \mathrm{AB}$, and SG: writing-review and editing. All authors have read and agreed to the published version of the manuscript.

anchovy and sardine as evidenced by Geostatistical and spatial indicators. PLoS ONE 10:e0135808. doi: 10.1371/journal.pone.0135808

Basilone, G., Ferreri, R., Barra, M., Bonanno, A., Pulizzi, M., Gargano, A., et al. (2020). Spawning ecology of the European anchovy (Engraulis encrasicolus) in the Strait of Sicily: linking variations of zooplankton prey, fish density, growth, and reproduction in an upwelling system. Prog. Oceanogr. 184:102330. doi: 10.1016/j.pocean.2020.102330

Basilone, G., Ganias, K., Ferreri, R., D’Elia, M., Quinci, E. M., Mazzola, S., et al. (2015). Application of GAMs and multinomial models to assess the spawning pattern of fishes with daily spawning synchronicity: a case study in the European anchovy (Engraulis encrasicolus) in the central Mediterranean Sea. Fish. Res. 167, 92-100. doi: 10.1016/j.fishres.2015.01.017

Basilone, G., Guisande, C., Patti, B., Mazzola, S., Cuttitta, A., Bonanno, A., et al. (2004). Linking habitat conditions and growth in the European anchovy (Engraulis encrasicolus). Fish. Res. 68, 9-19. doi: 10.1016/j.fishres.2004.02.012 
Basilone, G., Mangano, S., Pulizzi, M., Fontana, I., Giacalone, G., Ferreri, R., et al. (2017). European anchovy (Engraulis encrasicolus) age structure and growth rate in two contrasted areas of the Mediterranean Sea: the paradox of faster growth in oligotrophic seas. Mediterr. Mar. Sci. 18, 504-516. doi: $10.12681 / \mathrm{mms} .2059$

Begg, G. A., Campana, S. E., Flower, A. J., and Suthers, I. M. (2005). Otolith research and application: current directions in innovation and implementation. Mar. Freshw. Res. 56, 477-483. doi: 10.1071/MF5111

Bonanno, A., Barra, M., Basilone, G., Genovese, S., Rumolo, P., Goncharov, S., et al. (2016). Environmental processes driving anchovy and sardine distribution in a highly variable environment: the role of the coastal structure and riverine input. Fish. Oceanogr. 25, 471-490. doi: 10.1111/fog.12166

Bonanno, A., Placenti, F., Basilone, G., Mifsud, R., Genovese, S., Patti, B., et al. (2014). Variability of water mass properties in the strait of sicily in summer period of 1998-2013. Ocean Sci. 10, 759-770. doi: 10.5194/os-10-759-2014

Bonanno, A., Zgozi, S., Basilone, G., Hamza, M., Barra, M., Genovese, S., et al. (2015). Acoustically detected pelagic fish community in relation to environmental conditions observed in the Central Mediterranean sea: a comparison of Libyan and Sicilian-Maltese coastal areas. Hydrobiologia 755, 209-224. doi: 10.1007/s10750-015-2234-0

Bromley, P. J. (2003). The use of market sampling to generate maturity ogives and to investigate growth, sexual dimorphism and reproductive strategy in central and south-western North Sea sole (Solea solea L.). ICES J. Mar. Sci. 60, 52-65. doi: 10.1006/jmsc.2002.1318

Brosset, P., Fromentin, J. M., Van Beveren, E., Lloret, J., Marques, V., Basilone, G., et al. (2017). Spatio-temporal patterns and environmental controls of small pelagic fish body condition from contrasted Mediterranean areas. Prog. Oceanogr. 151, 149-162. doi: 10.1016/j.pocean.2016.12.002

Brosset, P., Lloret, J., Muñoz, M., Fauvel, C., Van Beveren, E., Marques, V., et al. (2016). Body reserves mediate trade-offs between life-history traits: new insights from small pelagic fish reproduction. R. Soc. Open Sci. 3:160202. doi: $10.1098 /$ rsos. 160202

Coleman, F. C., Koenig, C. C., Huntsman, J. C., Musick, J. A., Eklund, A. M., McGovern, J. C., et al. (2000). Long-lived reef fishes: the grouper-snapper complex. Fisheries 25, 14-20. doi: 10.1577/1548-8446(2000)025<0014:LRF $>2$. $0 . \mathrm{CO} ; 2$

Costa, A. M. (2009). Macroscopic vs. microscopic identification of the maturity stages of female horse mackerel. ICES J. Mar. Sci. 66, 509-516. doi: 10.1093/icesjms/fsn216

D’Elia, M., Patti, B., Bonanno, A., Fontana, I., Giacalone, G., Basilone, G., et al. (2014). Analysis of backscatter properties and application of classification procedures for the identification of small pelagic fish species in the Central Mediterranean. Fish. Res. 149, 33-42. doi: 10.1016/j.fishres.2013.08.006

DeVlaming, V., Grossman, G., and Chapman, F. (1982). On the use of Gonosomatic index. Comp. Biochem. Physiol. A. 73, 31-39. doi: 10.1016/0300-9629(82)90088-3

European Court of Auditors Special Report (2020). Available online at: https:// www.eca.europa.eu/en/Pages/DocItem.aspx?did=57066 (latest access July 19, 2021)

FAO (2020). The State of Mediterranean and Black Sea Fisheries 2020. Rome: General Fisheries Commission for the Mediterranean.

Ferreri, R., Basilone, G., D’Elia, M., Traina, A., Saborido-Rey, F., and Mazzola, S. (2009). Validation of macroscopic maturity stages according to microscopic histological examination for European anchovy. Mar. Ecol. 30, 181-187. doi: 10.1111/j.1439-0485.2009.00312.x

Ferreri, R., Ganias, K., Genovese, S., Fontana, I., Giacalone, G., Bonanno, A., et al. (2016). Oocyte batch development and enumeration in the European anchovy (Engraulis encrasicolus). Mediterr. Mar. Sci. 17, 670-677. doi: $10.12681 / \mathrm{mms} .1693$

Ferreri, R., McBride, R. S., Barra, M., Gargano, A., Mangano, S., Pulizzi, M., et al. (2019). Variation in size at maturity by horse mackerel (Trachurus trachurus) within the central Mediterranean Sea: Implications for investigating drivers of local productivity and applications for resource assessments. Fish. Res. 211, 291-299. doi: 10.1016/j.fishres.2018. 11.026

Flores, A., Wiff, R., Ganias, K., Marshall, C. T., Ciencias, E. De, Ciencias, F. De, et al. (2019). Accuracy of gonadosomatic index in maturity classification and estimation of maturity ogive. Fish. Res. 210, 50-62. doi: 10.1016/j.fishres.2018.10.009
Ganias, K. (2009). Linking sardine spawning dynamics to environmental variability. Estuar. Coast. Shelf SciBiol.. 84, 402-408. doi: 10.1016/j.ecss.2009.07.004

Ganias, K. (ed.). (2014). Biology and Ecology of Sardines and Anchovies (1st Edn.). CRC Press. doi: 10.1201/b16682

Ganias, K., Lowerre-Barbieri, S. K., and Cooper, W. (2015). Understanding the determinate-indeterminate fecundity dichotomy in fish populations using a temperature dependent oocyte growth model. J. Sea Res. 96, 1-10. doi: 10.1016/j.seares.2014.10.018

Ganias, K., and Nunes, C. (2011). Bathymetric segregation of spawning stages in the Atlantic sardine Sardina pilchardus. 428, 235-244. doi: 10.3354/meps09066

Ganias, K., Somarakis, S., Koutsikopoulos, C., and Machias, A. (2007). Factors affecting the spawning period of sardine in two highly oligotrophic Seas. Mar. Biol. 151, 1559-1569. doi: 10.1007/s00227-006-0601-0

Garcia, A., and Perez de Rubin, J. (1998). Some Data on the Reproductive Biology of Sardina pilchardus From the Coast of Malaga (SW Spain) (March 1983-May 1984). Rapport du Congrès dela Commission Internationale pour l'Exploration Scientifiquede la Mer Méditerranée, 31, 272.

GFCM, T. G. F. C. for the M. (2009). Establishment of Geographical Sub-Areas in the GFCM Area Amending the Resolution GFCM/31/2007/2. 26-30.

Giannoulaki, M., Pyrounaki, M. M., Liorzou, B., Leonori, I., Valavanis, V. D., Tsagarakis, K., et al. (2011). Habitat suitability modelling for sardine juveniles (Sardina pilchardus) in the Mediterranean Sea. Fish. Oceanogr. 20, 367-382. doi: 10.1111/j.1365-2419.2011.00590.x

Gordo, L. S., Costa, A., Abaunza, P., Lucio, P., Eltink, A. T. G. W., and Figueiredo, I. (2008). Determinate vs. indeterminate fecundity in horse mackerel. Fish. Res. 89, 181-185. doi: 10.1016/j.fishres.2007.09.024

Huret, M., Tsiaras, K., Daewel, U., Skogen, M. D., Gatti, P., Petitgas, P., et al. (2019). Variation in life-history traits of European anchovy along a latitudinal gradient: a bioenergetics modelling approach. Mar. Ecol. Prog. Ser. 617, 95-112. doi: 10.3354/meps 12574

ICES (2008). Report of the Workshop on Small Pelagics (Sardina pilchardus, Engraulis encrasicolus) maturity stages (WKSPMAT). Ices Wkspmat R, 80.

ICES (2010). Report of the Workshop on estimation of maturity ogive in Norwegian spring spawning herring (WKHERMAT). Bergen:ICES CM 2010/ACOM:51, 47..

ICES (2019). Report of the Working Group on Southern Horse Mackerel, Anchovy and Sardine (WGHANSA). Ices C. 2014/ACOM, 21-26.

Iglesias, M., Carrera, P., and Muiño, R. (2003). Spatio-temporal patterns and morphological characterisation of multispecies pelagic fish schools in the North-Western Mediterranean Sea. Aquat. Living Resour. 16, 541-548. doi: 10.1016/j.aquliv.2003.07.003

Jørgensen, C., Enberg, K., Dunlop, E. S., Arlinghaus, R., Boukal, D. S., Brander, K., et al. (2007). Ecology: managing evolving fish stocks. Science 318, 1247-1248. doi: $10.1126 /$ science.1148089

Katara, I., Pierce, G. J., Illian, J., and Scott, B. E. (2011). Environmental drivers of the anchovy/sardine complex in the Eastern Mediterranean. Hydrobiologia 670, 49-65. doi: 10.1007/s10750-011-0693-5

Keznine, M., Analla, M., Aksissou, M., and El Meraoui, A. (2020). The reproduction and growth of the sardine Sardina pilchardus in West Mediterranean, Morocco. Egypt. J. Aquat. Biol. Fish. 24, 303-319. doi: 10.21608/ejabf.2020.98433

Khoufi, W., Ferreri, R., Jaziri, H., El Fehri, S., Gargano, A., Mangano, S., et al. (2014). Reproductive traits and seasonal variability of Merluccius merluccius from the Tunisian coast. J. Mar. Biol. Assoc. U. K. 94, 1545-1556. doi: $10.1017 /$ S0025315414000356

Kjesbu, O. S., and Witthames, P. R. (2007). Evolutionary pressure on reproductive strategies in flatfish and groundfish: rrelevant concepts and methodological advancements. J. Sea Res. 58, 23-34. doi: 10.1016/j.seares.2007.02.001

Kuparinen, A., and Merilä, J. (2007). Detecting and managing fisheries-induced evolution. Trends Ecol. Evol. 22, 652-659. doi: 10.1016/j.tree.2007.08.011

Lappalainen, A., Saks, L., Šuštar, M., Heikinheimo, O., Jürgens, K., Kokkonen, E., et al. (2016). Length at maturity as a potential indicator of fishing pressure effects on coastal pikeperch (Sander lucioperca) stocks in the northern Baltic Sea. Fish. Res. 174, 47-57. doi: 10.1016/j.fishres.2015.08.013

Le Cren, E. D. (1951). The length-weight relationship and seasonal cycle in gonad weight and condition in the Perch (Perca fluviatilis). J. Anim. Ecol. 20, 201-219. doi: $10.2307 / 1540$

Lleonart, J., and Maynou, F. (2003). Fish stock assessments in the Mediterranean: state of the art. Sci. Mar. 67, 37-49. doi: 10.3989/scimar.2003.67s137 
Lloret, J., Faliex, E., Shulman, G. E., Raga, J. A., Sasal, P., Muñoz, M., et al. (2012). Fish health and fisheries, implications for stock assessment and management: the mediterranean example. Rev. Fish. Sci. 20, 165-180. doi: 10.1080/10641262.2012.695817

Lloret, J., Gil de Sola, L., Souplet, A., and Galzin, R. (2002). Effects of large-scale habitat variability on condition of demersal exploited fish in the North-Western Mediterranean. ICES J. Mar. Sci. 59, 1215-1227. doi: 10.1006/jmsc.2002.1294

Lluch-Belda, D., Crawford, R. J. M., Kawasaki, T., MacCall, A. D., Parrish, R. H., Schwartzlose, R. A., et al. (1989). World-wide fluctuations of sardine and anchovy stocks: the regime problem. S. Afr. J. Mar. Sci. 8, 195-205. doi: 10.2989/02577618909504561

Marshall, C. T., Frank, K. T. (1999). The effect of interannual variation in growth and condition on haddock recruitment. Can. J. Fish. Aquat. Sci. 56, 356-363.

Marshall, C. T., and McAdam, B. J. (2007). Integrated perspectives on genetic and environmental effects on maturation can reduce potential for errors of inference. Mar. Ecol. Prog. Ser. 335, 301-310. doi: 10.3354/meps335301

McBride, R. S., Somarakis, S., Fitzhugh, G. R., Albert, A., Yaragina, N. A., Wuenschel, M. J., et al. (2015). Energy acquisition and allocation to egg production in relation to fish reproductive strategies. Fish Fish. 16, 23-57. doi: 10.1111/faf.12043

McBride, R. S., Wuenschel, M. J., Nitschke, P., Thornton, G., and King, J. R. (2013). Latitudinal and stock-specific variation in size- and age-at-maturity of female winter flounder, Pseudopleuronectes americanus, as determined with gonad histology. J. Sea Res. 75, 41-51. doi: 10.1016/j.seares.2012.04.005

McFadden, D. (1974). Conditional logit analysis of qualitative choice behavior. Front. Ecometrics New York, NY: Academic Press, 105-142.

Morello, E. B., and Arneri, E. (2009). "Anchovy and sardine in the Adriatic Sea-an ecological review" in Oceanography and Marine Biology-An Annual Review, eds. R. N. Gibson, R. J. A. Atkinson, and J. D. M. Gordon (Boca Raton, FL: CRC Press), 209-255. doi: 10.1201/9781420094220.ch5

Morgan, M. J. (2018). Understanding biology to improve advice for fisheries management. ICES J. Mar. Sci. 75, 923-931. doi: 10.1093/icesjms/fsx229

Olsen, E. M., Heino, M., Lilly, G. R., Morgan, M. J., Brattey, J., Ernande, B., et al. (2004). Maturation trends indicative of rapid evolution preceded the collapse of northern cod. Nature 428, 932-935. doi: 10.1038/nature02430

Parrish, R. H., and Mallicoate, D. L. (1995). Variation in the condition factors of California pelagic fishes and associated environmental factors. Fish. Oceanogr. 4, 171-190. doi: 10.1111/j.1365-2419.1995.tb00070.x

Parrish, R. H., Serra, R., and Grant, W. S. (1989). The monotypic sardines, Sardina and Sardinops: their taxonomy, distribution, stock structure, and zoogeography. Can. J. Fish. Aquat. Sci. 46, 2019-2036. doi: 10.1139/f89-251

Pešić, A., Regner, S., Mandić, M., Ikica, Z., urović, M., Joksimović, A., et al. (2013). "Biological characteristics of anchovy (Engraulis encrasicolus) in Bokakotorska Bay (Montenegro)," in 6th Int. Conf. Water Fish, 197-203. Available online at: https://agris.fao.org/agris-search/search.do?recordID= RS2017000450 (accessed July 19, 2021).

R Core Team (2018). R: A Language and Environment for Statistical Computing. $\mathrm{R}$ Foundation for Statistical Computing, Vienna, Austria. Available online at: http://www.r-project.org (accessed July 19, 2021).

Rumolo, P., Bonanno, A., Barra, M., Fanelli, E., Calabrò, M., Genovese, S., et al. (2016). Spatial variations in feeding habits and trophic levels of two small pelagic fish species in the central Mediterranean Sea. Mar. Environ. Res. 115, 65-77. doi: 10.1016/j.marenvres.2016.02.004

SAC (2019). Scientific Advisory Committee on Fisheries (SAC) Working Group on Stock Assessment of Demersal Species (WGSAD). Rome: FAO, 1-68. Available online at: http://www.fao.org/gfcm/reports/technical-meetings/detail/en/c/ 1194087/ (accessed July 19, 2021).

Schwartzlose, R. A., Alheit, J., Bakun, A., Baumgartner, T. R., Cloete, R., Crawford, R. J. M., et al. (1999). Worldwide large-scale fluctuations of sardine and anchovy populations. S. Afr. J. Mar. Sci. 21, 289-347. doi: 10.2989/02577619978412 5962

Silva, A., Faria, S., and Nunes, C. (2013). Long-term changes in maturation of sardine, Sardina pilchardus, in Portuguese waters. Sci. Mar. 77, 429-438. doi: $10.3989 /$ scimar.03852.03A

Silva, A., Santos, M. B., Caneco, B., Pestana, G., Porteiro, C., Carrera, P., et al. (2006). Temporal and geographic variability of sardine maturity at length in the northeastern Atlantic and the western Mediterranean. ICES J. Mar. Sci. 63, 663-676. doi: 10.1016/j.icesjms.2006.01.005

Sinovčić, G., Keč, V. C., and Zorica, B. (2008). Population structure, size at maturity and condition of sardine, Sardina pilchardus (Walb., 1792), in the nursery ground of the eastern Adriatic Sea (Krka River Estuary, Croatia). Estuar. Coast. Shelf Sci. 76, 739-744. doi: 10.1016/j.ecss.2007.07.037

Somarakis, S., Ganias, K., Tserpes, G., and Koutsikopoulos, C. (2004) Ovarian allometry and the use of the gonosomatic index: a case study in the Mediterranean sardine, Sardina pilchardus. Mar. Biol. 146, 181-189. doi: 10.1007/s00227-004-1419-2

Thorson, J. T. (2015). Spatio-temporal variation in fish condition is not consistently explained by density, temperature, or season for California current groundfishes. Mar. Ecol. Prog. Ser. 526, 101-112. doi: 10.3354/meps11204

Torrejon-Magallanes, E. J. (2020). Package "sizeMat" v.1.1.2, Estimate Size at Sexual Maturity. Repository CRAN. Available online at: https://cran.r-project.org/ web/packages/sizeMat/vignettes/sizeMat.html

Tsikliras, A. C., Antonopoulou, E., and Stergiou, K. I. (2010). Spawning period of Mediterranean marine fishes. Rev. Fish Biol. Fish. 20, 499-538. doi: 10.1007/s11160-010-9158-6

Tsikliras, A. C., Dinouli, A., Tsiros, V. Z., and Tsalkou, E. (2015). The Mediterranean and Black Sea fisheries at risk from overexploitation. PLoS ONE 10, 1-19. doi: 10.1371/journal.pone.0121188

Tsikliras, A. C., and Koutrakis, E. T. (2013). Growth and reproduction of European sardine, Sardina pilchardus (Pisces: Clupeidae), in northeastern Mediterranean. Cah. Biol. Mar. 54, 365-374. doi: 10.21411/CBM.A.A5C85BA4

Vasilakopoulos, P., Maravelias, C. D., and Tserpes, G. (2014). The alarming decline of mediterranean fish stocks. Curr. Biol. 24, 1643-1648. doi: 10.1016/j.cub.2014.05.070

Véron, M., Duhamel, E., Bertignac, M., Pawlowski, L., Huret, M., and Baulier, L. (2020). Determinism of temporal variability in size at Maturation of Sardine Sardina pilchardus in the Bay of Biscay. Front. Mar. Sci. 7, 1-17. doi: 10.3389/fmars.2020.567841

Vila-Gispert, A., and Moreno-Amich, R. (2001). Fish condition analysis by a weighted least squares procedure: testing geographical differences of an endangered Iberian cyprinodontid. J. Fish Biol. 58, 1658-1666. doi: 10.1111/j.1095-8649.2001.tb02320.x

Walbaum, J. J. (1792). Petri Artedi Sueci genera piscium. In quibus systema totum ichthyologice proponitur cum classibus, ordinibus, generum characteribus, specierum differentiis, observationibus plurimis. Redactis speciebus 242 ad genera 52. Ichthyologice pars III. Cum tabulacenea. - pp. [1-7], 1-723, Tab.1-3Grypeswaldice. (Röse).

Watanabe, C., and Yatsu, A. (2006). Long-term changes in maturity at age of chub mackerel (Scomber japonicus) in relation to population declines in the waters off Northeastern Japan. Fish. Res. 78, 323-332. doi: 10.1016/j.fishres.2006.01.001

Wertheimer, A. C., Heard, W. R., Maselko, J. M., and Smoker, W. W. (2004). Relationship of size at return with environmental variation, hatchery production, and productivity of wild pink salmon in Prince William Sound, Alaska: does size matter? Rev. Fish Biol. Fish. 14, 321-334. doi: 10.1007/s11160-004-2942-4

Zavatarelli, M., Raicich, F., Bregant, D., Russo, A., and Artegiani, A. (1998). Climatological biogeochemical characteristics of the Adriatic Sea. J. Mar. Syst. 18, 227-263. doi: 10.1016/S0924-7963(98)00014-1

Zwolinski, J., Stratoudakis, Y., and Soares, E. (2001). Intra-annual variation in the batch fecundity of sardine off Portugal. J. Fish Biol. 58, 1633-1645. doi: 10.1111/j.1095-8649.2001.tb02318.x

Conflict of Interest: The authors declare that the research was conducted in the absence of any commercial or financial relationships that could be construed as a potential conflict of interest.

Publisher's Note: All claims expressed in this article are solely those of the authors and do not necessarily represent those of their affiliated organizations, or those of the publisher, the editors and the reviewers. Any product that may be evaluated in this article, or claim that may be made by its manufacturer, is not guaranteed or endorsed by the publisher.

Copyright (C) 2021 Basilone, Ferreri, Aronica, Mazzola, Bonanno, Gargano, Pulizzi, Fontana, Giacalone, Calandrino, Genovese and Barra. This is an open-access article distributed under the terms of the Creative Commons Attribution License (CC BY). The use, distribution or reproduction in other forums is permitted, provided the original author(s) and the copyright owner(s) are credited and that the original publication in this journal is cited, in accordance with accepted academic practice. No use, distribution or reproduction is permitted which does not comply with these terms. 